\title{
The Role of Parenting Styles on Neuroticism in Young Adults
}

\author{
Gabriela Carissa Averina ${ }^{1}$ Yang Adinda Zhafira $^{1}$ Venny $^{1}$ Brenda Corinna $^{1}$ \\ Jessica La Belle Emmanuela ${ }^{1}$ Meylisa Permata Sari ${ }^{1 *}$
}

\author{
${ }^{1}$ Faculty of Psychology, Tarumanagara University, Jakarta 11440, Indonesia \\ *Corresponding author. Email: meylisa.sari@fpsi.untar.ac.id
}

\begin{abstract}
Several studies have shown the risk of neuroticism to mental health and found that one of the factors in shaping personality is parenting styles. To date, however, no studies recorded have specifically examined the role of parenting styles on neuroticism in the Indonesian population. Therefore, this study aimed to provide empirical evidence of the relation between parenting styles and neuroticism in Indonesian young adults. 218 young adults with ages ranging from 18 to 25 years and resided in the Jakarta Metropolitan Area (Jakarta, Bogor, Depok, Tangerang, and Bekasi) participated in this study via online survey. Parenting style measured using Parental Bonding Instrument (PBI) and the Big Five Inventory (BFI) was used to evaluate participants' neuroticism. The results of the research analysis showed a significant correlation between parenting styles and neuroticism. In particular, it was found that affectionless control produced significantly higher levels of neuroticism in young adults than optimal parenting. In addition, parental care and protection were also found to be significantly associated with neuroticism. Implication of current research discussed in the article.
\end{abstract}

\section{Keywords: Parenting styles, personality, neuroticism, young adult}

\section{INTRODUCTION}

For decades, there has been a growing interest in psychological research on the role of personality in mental health, notably its detrimental effects. Personality traits are frequently discussed as risk factors for various psychopathological conditions. Neuroticism is often examined in the context of psychopathology [1]. Neuroticism can be interpreted as the tendency to experience more negative emotions, such as anger, sadness, and irritability [2]. Individuals with a high level of neuroticism tend to be more emotionally unstable and are prone to anxiety, tension, and vulnerability to negative influences [3]. Mainly due to the well-established association between high neuroticism and internalizing disorders like depression or anxiety disorders [2, 4, 5]. Similar to the personality variable, neuroticism has long been recognized since the beginning of basic science personality research and may even be the first domain of personality that was identified within psychology [6]. Neuroticism is impacting a wide array of psychopathological and health care concerns. It contributes to the occurrence of many significantly harmful life outcomes, as well as impairing the ability of persons to adequately address them.

Initially, personality traits were described to reflect genetically determined and relatively stable interindividual differences [7]. However, by now there is increasing evidence that personality changes in all periods of life with great developmental steps during adolescence, young adulthood and is possible to occur in old age $[8,9]$. There are various factors that are able to influence the development of one's personality and character. Based on previous studies conducted by Prinzie et al. [10], Huver et al. [11], and Kokkinos and Voulgaridou [12], it is stated that one of the factors that significantly influence an individual's personality development is perceived parenting style. Although the result of current study further establishes the effects of parenting style in levels of neuroticism in young adults [1], the implications of differences in personality maturation in relation to mental health and also the influence of perceived parenting styles on one's personality have not been well studied so far. Therefore, we intend to investigate further the role.

Based on the review of literature above, it can be argued that this topic in general has received a lot of attention from researchers globally. However, most of these studies were conducted outside Indonesia and there is still limited literature (barely none) regarding the relationship between parenting styles and neuroticism in young adults specifically in Indonesia. The various cultural differences that exist within Indonesia and also between Indonesia and other countries are the reasons why this topic should be reexamined with a sample of Indonesian citizens because with cultural differences, there are also differences in perceptions or perspectives [13] in understanding the concept of parenting itself. Besides the cultural differences, a majority of the studies have been done only in the 
adolescence population, while several studies serve evidence of changes in neuroticism not only during adolescence but also during young adults [1]. In accordance with the phenomena that have been described above, the focus of the study is to identify risk factors for developing neuroticism particularly in young adults. Hence, we hypothesized that different forms of neuroticism development in young adulthood are associated with differences in perceived parenting styles.

\subsection{Related Work}

Previous research consistently shows that parenting style is strongly associated with neuroticism. It is believed that one of the factors that significantly influence individual personality is parenting. In other words, there is a considerable influence on parenting patterns in individual personality development in adolescents and young adults. Parenting is one of the variables that has been researched extensively to collect more understanding of human development. In various conceptualizations, the values held by parents in carrying out their roles define the patterns of influence, practices, and values that occur naturally during parenting. According to Bowlby's attachment theory, parents who are apathetic to children's wants and needs for care and or inhibit children from achieving independence progressively cause children to form anxious attachments to parents and also to those around them [14]. Children who have anxious attachments grow up to be anxious, overly dependent, or immature and are at risk for developing psychiatric disorders, such as depression when under stress [14]. Based on the attachment theory, PBI was developed to assess the care and parental protection felt by children during the first 16 years of life [15]. By using scores from the care and protection dimensions, PBI classifies parenting styles into four categories, namely optimal parenting (high care and low protection), affectionate constraints (high care and high protection), affectionless control (low care and high protection), and neglectful parenting (low care and low protection).

An extensive review consistently shows that high neuroticism is a risk factor for the development of depression [2, 4]. The Diagnostic and Statistical Manual of Mental Disorders, Fifth Edition (DSM-5) explains that neuroticism is a strong influencing factor for the onset of major depressive disorder [16]. Therefore, it can be understood that a person's personality traits, particularly neuroticism, are closely related to the level of risk or tendency to experience depression. There are also several other studies that have generally though inconsistently show that neuroticism, irritability, mistrust, hostility, and other forms of negative emotions shown in individuals are associated with lack of warmth and tend to have experienced negative parenting, while agreeableness, extraversion, and conscientiousness are associated with more positive and adaptive parenting $[5,17,18]$.

\subsection{Our Contribution}

In this research, we will further study and examine the role of parenting styles that is believed to play a part in the increase of neurotic personality in young adults in Indonesia, specifically in Jakarta Metropolitan Area. We consider genetic and environmental influences for its development and also consider developmental considerations, including evidence for stability and change across the age range of 18-25 years old.

\subsection{Paper Structure}

This research paper is structured as such, Introduction, Methods, Results \& Discussion, and Conclusion. Each section addresses a different objective. Therefore, the paper is organized as follows: Section 1-in the Introduction; we portray the problem we intend to address by giving basic introductions, supportive statistics, and review of literature related to the research topic. Section 2, namely the Method section; contains several aspects on what we do to answer the research question, which includes procedure, sample, instrument, and data analysis. Section 3, which is the Results \& Discussion section, encompasses restatement of research questions and description of research results, followed by a discussion containing our interpretations about the results obtained from the research. Section 4 concludes the paper, discusses limitations of the study and presents direction for future research as well as suggestions for related parties.

\section{METHODS}

\subsection{Participants}

A total of 231 samples were collected for this study using convenience sampling technique, two of which were omitted due to numerous missing values on their questionnaires, another being an outlier. 228 subjects were included in the final analysis. The participants' age range spans from 18 to 25 years old $(M=20.13, S D=1.8)$ with their first 16 years raised by both parents and the designated locale is Jakarta Metropolitan Area. Before questionnaires were filled, participants were given an overview of this study that thoroughly explains its purpose and have to give consent. For their time and responses, five participants were randomly selected to win Rp 30.000,00 worth of OVO or Go-Pay e-money as a form of compensation.

In summary, a majority of the participants were women $(\mathrm{n}=168,73.7 \%)$, aged $19(\mathrm{n}=58,25.4 \%)$, residing in Jakarta $(\mathrm{n}=154,67.5 \%)$, living with parents $(\mathrm{n}=202,88.6 \%)$ and students $(n=196,86 \%)$. Most of the participants perceived that both paternal and maternal figures living harmoniously $(\mathrm{n}=161,70.6 \%)$. 


\subsection{Instruments}

The online questionnaire in this study utilizes two measurement tools (PBI \& BFI) and attempts to extract the demographic characteristics. The two measurement tools will be examined in more detail under the subsequent subchapters.

\subsubsection{Demographic characteristics}

In order to acquire the demographic characteristics, participants were required to fill in their personal information which include; name or initials, contact number, sex, age, city of residence, who do said participants live with (parents, guardian, friend, or alone), occupation and family condition (both parents are present and are living harmoniously, both parents are present and are living inharmoniously, parents divorced, father/mother deceased, father/mother remarried, or other).

\subsubsection{Parental bonding instrument}

The Parental Bonding Instrument was applied to determine the perceived parenting style that the participants experienced in their first 16 years. This instrument was developed by Parker et al. [15] and in this study we used the Indonesian version from Cahyani [19] with some adjustments made.

Two dimensions were measured which are care and protection in order to discover the parenting style that the participants underwent. These two dimensions are extracted from the participants' paternal and maternal side by including 25 questions for each side, 12 of which are intended to measure the level of care and the rest of the 13 questions are placed to measure the level of protection. Each question was given a scale as a method of answering, ranging from 0 that represents "Strongly Disagree" to 3 that represents "Strongly Agree". Lower score indicates a lower level of care and protection that the participants received from their parents. In order to determine the parenting style, the level of care and protection from both parents are divided into two categories which are "high" or "low". From the maternal side, in order for their care level to be labelled as "high", it has to achieve a minimum score of 27 and for their protection level to be considered as "high", a minimum score of 13.5 has to be achieved. For the paternal side, a score of 24 needs to be achieved in order to be labelled as highly caring while to be considered highly protective, a score of 12.5 needs to be present [15].

If the care and protection scores are low, the parenting style is neglectful parenting but if the care and protection scores are high then the parenting style is affectionate constraint. Furthermore, if the care level is low whilst the level of protection is high, the parenting style will be affectionless control. Lastly, if the care level is high paired with a low level of protection then the parenting style will be labelled as optimal parenting [15]. In the measurement of both dimensions, 12 reverse scored items were present and recoding was done for those items.
To conclude, the PBI shows high reliability when measuring its two dimensions (care $\&$ protection). On the paternal side, reliability for care measures at $\alpha=0.924$ while protection measures $\alpha=0.858$. On the maternal side, reliability for protection measures at $\alpha=0.907$ while protection measures $\alpha=0.818$.

\subsubsection{Big five inventory - neuroticism}

The Big Five Inventory is used in this study to measure neuroticism. This instrument was developed by John [20] and has been reliably adapted by Ramdhani [21] into Indonesian. BFI aims to measure the five dimensions of an individual's personality, among them is neuroticism [22]. In order to measure the level of neuroticism, eight questions were fielded and three of them are reverse scored items. Participants had five answers to choose from in every question ranging from 0 to 5, 0 being "Strongly Disagree" and 5 being "Strongly Agree". The higher the score, the higher the level of neuroticism is.

\subsection{Analysis Technique}

To start the analytical process, the data was filtered by verifying the data normality and rooting out any missing values. Individuals with data that are askew from the normal spread of the sample were then excluded from the analytical process. Subsequently, reverse scored items from each instrument were re-coded. In order to ensure maximum reliability in each measuring instrument, a minimum score of 'item-total correlation' was set to 0.20 for every item in the questionnaire [23].

Once the reliability of each question had been established, we calculated the scores of parental care \& protection and participants' neuroticism. Furthermore, assumption tests were conducted on data normality, linearity, and homoscedasticity. Based on the assumption tests, we decided upon utilizing parametric tests for the data analysis. Descriptive tests were then conducted to obtain the mean score and standard deviation from the measured variables. To further assess the data, we calculated the mean score of neuroticism for each demographic characteristics and then ran a comparison test by using an independent sample TTest and one-way analysis of variance (ANOVA) between subjects. We performed Pearson's correlation test to acquire the significance of the correlation between participants' neuroticism and the level of care and protection amongst their parents. In addition, we categorized the total score of parental care and protection into four different parenting styles: Optimal parenting (high care \& low protection), affectionate constraint (high care \& high protection), affectionless control (low care \& high protection), and neglectful parenting (low care \& low protection)

One-way ANOVA was then applied to gain information on the number of participants and the mean score for neuroticism on each parenting style. The final analysis was done by comparing the level of neuroticism in each parenting style from the paternal and the maternal side through post-hoc test using Tukey method. Through this 
test, we established the significant differences in neuroticism level in between each parenting style paternally and maternally. We conducted every test and calculation using IBM SPSS Statistics 15.0 for Windows. The level of statistically significant differences was set at $p<0.05$.

\section{RESULT AND DISCUSSION}

\subsection{Descriptive Statistics}

In Table 1 , it is evident that affectionless control is the dominant parenting style in fathers among our samples $(\mathrm{n}=71,31.1 \%)$. On the maternal side, optimal parenting is the dominant parenting style $(n=72,31.6 \%)$. Based on the categorization of parents' care \& protection into "low" or "high" in the PBI, the average care for fathers is "low" ( $M$ $=22.44, S D=8.969)$, the average care for mothers is also "low" $(M=26.08, S D=7.563)$. However, we discovered that fathers and mothers achieve a "high" level of protection with fathers at $(M=14.04, S D=7.801)$ and mothers at $(M$ $=14.90, S D=7.059)$.

Parametric tests were utilized to sort the neuroticism level by each demographic characteristic. We applied independent sample T-Test to establish the difference between the level of neuroticism in male and female. The result shows that men experience lower level of neuroticism significantly $(M=24.33, S D=5.807)$ when compared to women $(M=26.39, S D=5.577, F=0.119, p=0.016)$ which means sex is one variable that affects an individual's neuroticism level. According to Brizendine [24] men and women handle stress and conflict differently. Women release negative hormones when presented with conflict and stress, this hormone release causes stress, anxiety and fear whereas men perceive conflict as a challenge. This concept verifies our findings that sex determines an individual's level of neuroticism.

Furthermore, one-way ANOVA is performed to analyse mean differences of neuroticism score based on age, city of residence, housemate, occupation and family condition. The results as shown in Table 1 indicate that significant differences in neuroticism levels are only found in between participants' occupations $(F=2.733, p=0.020)$. Among the listed occupations on Table 1 , teachers experienced the highest level of neuroticism $(M=38)$. Another important finding is that there is a significant difference $(p=0.037)$ in level of neuroticism between the participants who have a paternal and maternal figure living harmoniously $(M=25.34, S D=5.815)$ as compared to those who have a paternal and maternal figure but are in an inharmonious household $(M=28.44, S D=4.942)$

The difference in neuroticism level can be explained by genetic and environmental factors [25, 26]. Lahey [25] argued that an individual's environment in which they were raised plays a larger part in influencing an individual's neuroticism level in their young adulthood. Lahey further clarified that the environment includes one's interaction and relationship with nuclear and extended family, friends, and others. This concept is crucial in understanding the increase in neuroticism level as most individuals adjust to their external environment in the transition between adolescent to adulthood [27]. Individuals that fail to achieve the expected standard whether set externally or internally will experience increased inner tension and conflict that might not be resolved quickly. The inner conflict might cause an individual to act on the negative emotions or act neurotically, a study by Nakao et al. [28] states that the chance that an individual acts irrationally or neurotically in their adulthood increases or decreases depending on the type and quality of parenting that the individual received, this also affects one's attitude and development as a whole. This is very likely because the inner family is the first contact in an individual's developmental phase for most of the time. In addition, Stuart [29] argued that an individual's occupation or daily activities can cause an increase in neuroticism level due to added stress to their life.

Finally, the significant difference in neuroticism level between individuals that live with a complete and harmonious family and individuals that live with incomplete and inharmonious family is supported by Hurlock in Jasmiah [30] who stated that individuals that was raised in a harmonious family tend to have lesser conflict with parents as opposed to individuals that was raised in an inharmonious family.

\subsection{Dimensions of Parenting Style and Neuroticism}

We applied Pearson's correlation test to establish a link in between parental care and protection with participants' neuroticism level. The results indicated significant negative correlation in between father's care $(r=-0.219, p=0.001)$ and mother's care $(r=-0.383, p<0.001)$ with the level of neuroticism. Furthermore, positive and significant correlation between father's protection $(r=0.219, p=$ $0.001)$ and mother's protection $(r=0.261, p<0.001)$ with neuroticism is found. These results indicate that there is a correlation between parental care \& protection and neuroticism, which is shown in the lowered neuroticism level as the care gets higher. On the other hand, the higher the protection level, the higher the neuroticism level is.

Parents' level of care \& protection and their quality of relationship with their child are considered important pillars in a child's personality development, which explains their immense impact on a child's level of neuroticism in the later part of their life [28, 31]. This is especially true with mothers [32]. The family's emotional and psychological landscape are also impactful to the development of a child's personality, attitude and characteristics $[28,33]$. 
Table 1 Demographic characteristics, perceived parenting styles, parents' level of care \& protection, participant's level of neuroticism, and correlation between demographic characteristics and neuroticism.

\begin{tabular}{|c|c|c|c|}
\hline $\begin{array}{l}\text { Characteristics or } \\
\text { Measured Variables }\end{array}$ & Value (n, \%) & $\begin{array}{c}\text { Neuroticism Score } \\
(\text { Mean } \pm \text { SD) }\end{array}$ & p-value \\
\hline $\begin{array}{l}\text { 1. Sex } \\
\text { Male } \\
\text { Female }\end{array}$ & $\begin{array}{c}60,26.3 \% \\
168,73.7 \%\end{array}$ & $\begin{array}{l}24.33 \pm 5.807 \\
26.39 \pm 5.577\end{array}$ & 0.016 \\
\hline $\begin{array}{l}\text { 2. Age } \\
18 \\
19 \\
20 \\
21 \\
22 \\
23 \\
24 \\
25\end{array}$ & $\begin{array}{l}48,21.1 \% \\
58,25.4 \% \\
25,11 \% \\
57,25 \% \\
15,6.6 \% \\
11,4.8 \% \\
6,2.6 \% \\
8,3.5 \%\end{array}$ & $\begin{array}{l}26.48 \pm 5.169 \\
25.83 \pm 5.164 \\
26.28 \pm 5.054 \\
25.60 \pm 6.563 \\
27.27 \pm 5.750 \\
23.82 \pm 4.875 \\
24.83 \pm 5.419 \\
23.63 \pm 9.054\end{array}$ & 0.717 \\
\hline $\begin{array}{l}\text { 3. City of residence } \\
\text { Jakarta } \\
\text { Bogor } \\
\text { Depok } \\
\text { Tangerang } \\
\text { Bekasi }\end{array}$ & $\begin{array}{l}154,67.5 \% \\
11,4.8 \% \\
4,1.8 \% \\
38,16.7 \% \\
21,9.2 \%\end{array}$ & $\begin{array}{l}26.15 \pm 5.662 \\
23.91 \pm 5.594 \\
27.75 \pm 2.630 \\
25.95 \pm 6.080 \\
24.14 \pm 5.624\end{array}$ & 0.403 \\
\hline $\begin{array}{l}\text { 4. Housemate } \\
\text { With parents } \\
\text { With guardian } \\
\text { With friend } \\
\text { Alone (in boarding house/apartment/other) }\end{array}$ & $\begin{array}{l}202,88.6 \% \\
5,2.2 \% \\
1,0.4 \% \\
20,8.8 \%\end{array}$ & $\begin{array}{l}26.13 \pm 5.670 \\
27 \pm 5.196 \\
23 \\
22.85 \pm 5.575\end{array}$ & 0.089 \\
\hline $\begin{array}{l}\text { 5. Occupation } \\
\text { Student } \\
\text { Private sector employee } \\
\text { Entrepreneur } \\
\text { Entrepreneur and Student } \\
\text { Job seeker } \\
\text { Teacher }\end{array}$ & $\begin{array}{l}196,86 \% \\
18,7.9 \% \\
9,3.9 \% \\
1,0.4 \% \\
3,1.3 \% \\
1,0.4 \%\end{array}$ & $\begin{array}{c}26.06 \pm 5.456 \\
26.22 \pm 6.567 \\
21.33 \pm 6.205 \\
22 \\
21 \pm 7 \\
38\end{array}$ & 0.020 \\
\hline $\begin{array}{l}\text { 6. Family condition }{ }^{\mathrm{a}, \mathrm{b}} \\
\text { Both parents present and living harmoniously } \\
\text { Both parents present and living inharmoniously } \\
\text { Parents divorced } \\
\text { Father/mother deceased } \\
\text { Father/mother remarried } \\
\text { Both parents remarried }\end{array}$ & $\begin{array}{l}161,70.6 \% \\
36,15.8 \% \\
10,4.4 \% \\
17,7.5 \% \\
2,0.9 \% \\
2,0.9 \%\end{array}$ & $\begin{array}{c}\mathbf{2 5 . 3 4} \pm \mathbf{+ 5 . 8 1 5} \\
\mathbf{2 8 . 4 4} \pm \mathbf{4 . 9 4 2} \\
26.10 \pm 5.174 \\
25.47 \pm 5.680 \\
22 \pm 0 \\
26 \pm 5.657\end{array}$ & 0.081 \\
\hline $\begin{array}{l}\text { 7. Parenting style (Father) } \\
\text { Affectionate Constraint } \\
\text { Optimal Parenting } \\
\text { Affectionless Control } \\
\text { Neglectful Parenting }\end{array}$ & $\begin{array}{l}53,23.3 \% \\
60,26.3 \% \\
71,31.1 \% \\
44,19.3 \%\end{array}$ & & \\
\hline $\begin{array}{l}\text { 8. Parenting style (Mother) } \\
\text { Affectionate Constraint } \\
\text { Optimal Parenting } \\
\text { Affectionless Control } \\
\text { Neglectful Parenting }\end{array}$ & $\begin{array}{c}56,24.6 \% \\
72,31.6 \% \\
68,29.8 \% \\
32,14 \%\end{array}$ & & \\
\hline $\begin{array}{l}\text { 9. Father's Care } \\
\text { 10. Mother's Care } \\
\text { 11. Father's Protection } \\
\text { 12. Mother's Protection } \\
\text { 13. Neuroticism }\end{array}$ & $\begin{array}{l}22.44 \pm 8.969 \\
26.08 \pm 7.563 \\
14.04 \pm 7.801 \\
14.90 \pm 7.059 \\
25.85 \pm 5.698\end{array}$ & & \\
\hline
\end{tabular}

a Harmonious and inharmonious based on participants' perception of the relationship between their parents, ${ }^{\mathrm{b}}$ Significant difference in level of neuroticism is found in participants who have a paternal and maternal figure living harmoniously as compared to those who have a paternal or maternal figure but are in an inharmonious household. This figure stands at $p=$ 0.037 . 


\subsection{Parenting Style and Neuroticism}

To discover the relationship between parenting style and participants' neuroticism level, we utilized one-way ANOVA and post hoc analysis towards the maternal and paternal parenting style separately. The results presented in Table 2 show that there is a significant difference in neuroticism between the four paternal parenting styles $(F=$ $3.155, p<0.05)$ and the four maternal parenting styles $(F=$ 9.584, $p<0.001)$. Moreover, analysis result towards the paternal parenting style indicates that participants who received affectionless control parenting style $(M=27.17$, $S D=5.326)$ experience a higher level of neuroticism $(M D$ $=3.019, p<0.05)$ as opposed to participants who received optimal parenting $(M=24.15, S D=6.251)$ from their father. However, there is no significant difference in the mean scores of neuroticism amongst other paternal parenting styles. From the maternal side, analysis indicates that participants who received affectionless control from their mother $(M=28.32, S D=5.448)$ produce a significantly higher level of neuroticism $(p<0.05)$ in comparison to affectionate constraint $(M=24.93, S D=4.604)$ and optimal parenting $(M=23.71, S D=5.658)$. Neglectful parenting from mothers $(M=27.03, S D=5.970)$ also causes a significantly higher level $(M D=3.323, p<0.05)$ of neuroticism amongst the participants compared to optimal parenting. These various results show that there is a strong correlation between participants' neuroticism level and their parents' parenting style.

These findings are supported by previous studies which state that parenting styles are one of the most important factors in a child's personality development towards their adult phase [10, 11, 12]. A study by Takahashi et al. [18] discovered that increased neuroticism in young adults is closely related to affectionless control and neglectful parenting styles. Furthermore, this study [18] specifically stated that individuals who experienced optimal parenting have a significantly lower neuroticism level than individuals who received affectionless control parenting style from their parents, this result is consistent with ours. Personality studies consistently find that neuroticism, irritability, mistrust, hostility, and other forms of negative emotions are linked to an indifferent and negative upbringing. Meanwhile, agreeableness, extraversion and conscientiousness are linked to a more adaptive and positive upbringing $[5,17,18]$. A negative parenting style is prone to inflict psychological issues in children once they reach young adulthood. Children who were exposed to low emotional warmth, overprotectiveness and inconsistent disciplinary systems are prone to developing psychological issues in the future such as depression, anxiety, low selfesteem, somatic complaints and hostility [34]. Edwards [35] established that parenting style plays an important part in how children cope with stressors in their life.

In addition, the implications of these findings are discussed. From this study, it can be learned that neuroticism is the result of not only individual factors, but also variables involving parenting styles, home life, and community surroundings. Therefore, we suggest several implications: (a) Attention should be focused on the interaction effects involving personality traits and parenting styles; (b) Perceived parenting styles moderate the effects of neuroticism (neurotic personality) specifically on young adults; and (c) People with problematic family relations experience greater discontentment and negative mood related to personality traits and also show more signs of involvement in neuroticism.

This study provides insight on how parents greatly impact the development of children as they serve the role of providing positive affirmations, love, and respect. Thereupon, this study is also expected to help parents in understanding their crucial parental influences that could affect the personality, behavior, and well-being of their children. More research will in fact be necessary to refine and further elaborate our findings.

\section{CONCLUSION}

From all the evidence above, it can be ascertained that children's neurotic tendency is very dependent on parents' parenting style. Therefore, the results of this study support the hypothesis that parenting style is correlated with neuroticism in young adults.

Table 2 Correlation between parenting styles and neuroticism

\begin{tabular}{lccc}
\hline \multicolumn{1}{c}{ Parenting Style } & Total Participants (n) & $\begin{array}{c}\text { Neuroticism } \\
(\text { Mean } \pm \text { SD) }\end{array}$ & p-value \\
\hline Father & 53 & & 0.026 \\
Affectionate Constraint & 60 & $26.04 \pm 5.000$ & \\
Optimal Parenting & 71 & $24.15 \pm 6.251$ & \\
Affectionless Control & 44 & $25.17 \pm 5.326$ & \\
Neglectful Parenting & & & \\
Mother & 56 & $24.93 \pm 4.604$ & \\
Affectionate Constraint & 72 & $23.71 \pm 5.658$ & \\
Optimal Parenting & 68 & $28.32 \pm 5.448$ & \\
Affectionless Control & 32 & $27.03 \pm 5.970$ & \\
Neglectful Parenting & & & \\
\hline
\end{tabular}

It also supported the findings from previous studies that found affectionless control parenting style in particular led to higher levels of neuroticism, due to lack of care and high protection in parenting practices. 
The first limitation of this study is that researchers used a questionnaire based on the participants' memory during the first 16 years of their life which may cause a memory bias. However, evidence shows test-retest consistency and validity which can be concluded that PBI has good psychometric property [15]. Secondly, the number of samples of current study considered insufficient to describe the real population and less representative of young adults in general since the study only participated by college students. Thirdly, participants of this study are mentally healthy in general; therefore the results may not be applicable to individuals with psychological disorder.

Suggestions for further research are as follows: conducting a longitudinal study to see changes gradually and comparing the results from populations with clinical conditions and populations with no clinical conditions to see if there is any significant difference.

In addition, the practical advices or concrete steps for the parties involved in this study, more specifically for parents are: (1) Adjusting parenting style to children's needs, because each child has different kinds of needs and parents are required to be able to fulfill those needs accordingly; and (2) We suggest that parents cultivate effective communication with their children with the aim of establishing closeness and warmth between family members.

\section{ACKNOWLEDGMENTS}

This study was supported by the Faculty of Psychology, Tarumanagara University, Jakarta, Indonesia.

\section{REFERENCES}

[1] M. Aldinger, M. Stopsack, I. Ulrich, K. Appel, E. Reinelt, S. Wolff, H.J. Grabe, S. Lang, S. Barnow. Neuroticism developmental courses - implications for depression, anxiety and everyday emotional experience; a prospective study from adolescence to young adulthood. BMC Psychiatry. 14(210) (2014). DOI: $10.1186 / \mathrm{s} 12888$ 014-0210-2

[2] J. Ormel, B. F. Jeronimus, R. Kotov, H. Riese, E.H. Bos, B. Hankin, J.G.M. Rosmalen, A.J. Oldehinkel. Neuroticism and common mental disorders: Meaning and utility of a complex relationship. Clinical Psychology Review. 33(5) (2013) 686-697. DOI: 10.1016/j.cpr.2013.04.003

[3] J. Vondra, J. Belsky. Developmental origins of parenting: Personality and relationship factors. In: T. Luster \& L. Okagaki (Eds.), Parenting: An Ecological Perspective, Erlbaum, New York, 1993, pp. 1-33.

[4] D. N. Klein, R. Kotov, S.J. Bufferd. Personality and depression: Explanatory models and review of the evidence.
Annual Review of Clinical Psychology. 7 (2011) 269-295. DOI: 10.1146/annurev-clinpsy-032210-104540

[5] Y. Ono, Y. Takaesu, Y. Nakai, M. Ichiki, J. Masuya, I. Kusumi, T. Inoue. The influence of parental care and overprotection, neuroticism and adult stressful life events on depressive symptoms in the general adult population. Journal of Affective Disorders. 217 (2017) 66-72. DOI: 10.1016/j.jad.2017.03.058

[6] T. A. Widiger, J.R. Oltmanns. Neuroticism is a fundamental domain of personality with enormous public health implications. World Psychiatry. 16(2) (2017) 144 145. DOI: $10.1002 / w p s .2041$

[7] C. R. Cloninger. A psychobiological model of temperament and character. Archives of General Psychiatry. 50(12) (1993) 975. DOI: 10.1001/archpsyc. 1993.01820240059008

[8] A. Caspi, B. W. Roberts, R. L. Shiner. Personality development: Stability and change. Annual Review of Psychology. 56(1) (2005) 453-484. DOI: 10.1146/annurev.psych.55.090902.141913

[9] J. Specht, B. Egloff, S. C. Schmukle. Stability and change of personality across the life course: The impact of age and major life events on mean-level and rank-order stability of the Big Five. Journal of Personality and Social Psychology. 101(4) (2011) 862-882. DOI: $10.1037 / \mathrm{a} 0024950$

[10] P. Prinzie, P. Onghena, W. Hellinckx, H. Grietens, P. Ghesquière, H. Colpin. The additive and interactive effects of parenting and children's personality on externalizing behaviour. European Journal of Personality. 17(2) (2002) 95-117. DOI: 10.1002/per.467

[11] R. M. E. Huver, R. Otten, H. de Vries, R.C.M.E. Engels. Personality and parenting style in parents of adolescents. Journal of Adolescence. 33(3) (2010) 395402. DOI: $10.1016 /$ j.adolescence.2009.07.012

[12] C. M. Kokkinos, I. Voulgaridou. Links between relational aggression, parenting and personality among adolescents. European Journal of Developmental Psychology. 14(3) (2016) 249-264. DOI: 10.1080/17405629.2016.1194265

[13] S. Wu, B. Keysar. The effect of culture on perspective taking. Psychological Science. 18(7) (2007) 600-606. DOI: 10.1111/j.1467-9280.2007.01946.x

[14] J. Bowlby. The making and breaking of affectional bonds. I. Aetiology and psychopathology in the light of attachment theory. British Journal of Psychiatry. 130 (1977) 201-210. DOI: 10.1192/bjp.130.3.201

[15] G. Parker, H. Tupling, L.B. Brown. A Parental Bonding Instrument. British Journal of Medical 
Psychology. 52 (1979) 1-10. DOI: 10.1111/j.20448341.1979.tb02487.x

[16] American Psychiatric Association. Diagnostic and statistical manual of mental disorders: DSM-5 (5th ed.). American Psychiatric Association Publishing (2013). DOI: 10.1176/appi.books.9780890425596

[17] J. L. Koenig, R. A. Barry, G. Kochanska. Rearing difficult children: Parents' personality and children's proneness to anger as predictors of future parenting. Parenting. 10(4) (2010) 258-273. DOI: $10.1080 / 15295192.2010 .492038$

[18] N. Takahashi, A. Suzuki, Y. Matsumoto, T. Shirata, K. Otani. Perceived parental affectionless control is associated with high neuroticism. Neuropsychiatric Disease and Treatment. 13 (2017) 1111-1114. DOI: 10.2147/NDT.S132511

[19] W. N. I. Cahyani. Hubungan Parental Bonding dan Self-Esteem dengan Perilaku Seksual pada Remaja, Bachelor's Thesis, Universitas Airlangga, 2017. http://repository.unair.ac.id/76637/

[20] O. P. John. The "Big Five" factor taxonomy: Dimensions of personality in the natural language and in questionnaires. In: L.A. Pervin (Ed.), Handbook of Personality: Theory and Research, 2nd ed., Guilford Press, New York, 1990, pp. 66-100.

[21] N. Ramdhani. Adaptasi bahasa dan budaya inventori Big Five. Jurnal Psikologi. 39(2) (2012) 189-207. DOI: 10.22146/jpsi.6986

[22] O. P. John, S. Srivastava. The Big-Five trait taxonomy: History, measurement, and theoretical perspectives. In: L.A. Pervin \& O.P. John (Eds.), Handbook of Personality: Theory and Research, Guilford Press, New York, 1999, pp. 102-138.

[23] P. Kline. A handbook of test construction: Introduction to psychometric design. Methuen, London. 1986.

[24] L. Brizendine. The female brain. Morgan Road Books, New York. 2007.

[25] B. B. Lahey. Public health significance of neuroticism. American Psychologist. 64(4) (2009) 241-256. DOI: 10.1037/a0015309

[26] S. Wang, R.L. Repetti, B. Campos. Job stress and family social behavior: The moderating role of neuroticism. Journal of Occupational Health Psychology. 16(4) (2011) 441-456. DOI: $10.1037 / \mathrm{a} 0025100$

[27] C. Zahn-Waxler. Environment, biology, and culture: Implications for adolescent development. Developmental Psychology, 32(4) (1996) 571-573. DOI: 10.1037/00121649.32.4.571
[28] K. Nakao, J. Takaishi, K. Tatsuta, H. Katayama, M. Iwase, K. Yorifuji, M. Takeda. The influences of family environment on personality traits. Psychiatry and Clinical Neurosciences. 54(1) (2000) 91-95. DOI: 10.1046/j.14401819.2000.00642.x

[29] G. W. Stuart. Buku saku keperawatan jiwa. Fifth Edition. EGC, Jakarta. 2007.

[30] Y. Jasmiah. Keluarga Harmonis dan Implikasinya terhadap Pembentukan Kepribadian Anak Usia Dini, Bachelor's Thesis, Fakultas Keguruan dan Ilmu Pendidikan Universitas Tanjungpura, 2010.

[31] A.K.M.R. Karim, T. Begum. The Parental Bonding Instrument: A psychometric measure to assess parenting practices in the homes in bangladesh. Asian Journal of Psychiatry. 25 (2017) 231-239. DOI: 10.1016/j.ajp.2016.11.004

[32] C. J. M. Buschgens, M.A.G. van Aken, S.H.N. Swinkels, J. Ormel, F.C. Verhulst, J.K. Buitelaar. Externalizing behaviors in preadolescents: Familial risk to externalizing behaviors and perceived parenting styles. European Child \& Adolescent Psychiatry. 19(7) (2009) 567-575. DOI: 10.1007/s00787-009-0086-8

[33] J. Jaureguizar, E. Bernaras, P. Bully, M. Garaigordobil. Perceived parenting and adolescents' adjustment. Psicologia: Reflexão e Crítica. 31(1) (2018). DOI: $10.1186 / \mathrm{s} 41155-018-0088-\mathrm{x}$

[34] L. D. Rocha, K. van Putten, P.P. Moormann. The impact of parental styles on the development of psychological complaints. Europe's Journal of Psychology. 11(1) (2015) 155-168. DOI: 10.5964/ejop.v11i1.836

[35] C. D. Edwards. Ketika anak sulit diatur: Panduan orangtua mengubah masalah perilaku anak. Second Edition. Kaifa, Bandung. 2006. 